\title{
Connexin43 Gap Junctions Influences Osteoblast Signalling and Enhances Osteoarthritis Gene Expression
}

\section{Aditi Gupta*}

Research Associate Faculty of the School of Medicine at University of Maryland, Baltimore, USA

${ }^{*}$ Corresponding author: Aditi Gupta, Research Associate Faculty of the School of Medicine at University of Maryland, Baltimore, USA; E-mail: agupta@umoa.umm.edu

Received date: April 29, 2016; Accepted date: May 02, 2016; Published date: May 05, 2016

Citation: Gupta A (2016) Connexin43 Gap Junctions Influences Osteoblast Signalling and Enhances Osteoarthritis Gene Expression. J Clin Exp Orthop 2: 2. doi: 10.4172/2471-8416.100016

Copyright: (c) 2016 Gupta A. This is an open-access article distributed under the terms of the Creative Commons Attribution License, which permits unrestricted use, distribution, and reproduction in any medium, provided the original author and source are credited.

\section{Editorial}

In multicellular organism, cells communicate with each other by gap junctions. The subunits of gap junction channels are proteins called connexins. Six-connexin proteins interact to form a ring-like pore structure called a hemichannel or connexon; these hemichannels dock to hemichannels on neighbouring cells, forming a gap junction's pore, which provides a direct intercellular passage for small molecules or ion to move between cells $[1,2]$.

Gap junction communication plays a critical role in bone cells such as osteoblast, osteocytes and osteoclast [3]. In humans, more than twenty connexins have been identified but Cx43, Cx45, Cx40, Cx46 and Cx37 are expressed in the bone. Most of the gap junction possesses four transmembrane regions, with cytoplasmic amino and carboxyl regions.

Notably, Cx43, encoded by the Gja1 gene, is the most abundantly expressed connexin in bone, and has an important role in maintaining bone homeostasis [4]. Multiple evidences have suggested that gap junction communication is important for cell growth and differentiation. Mutations in Cx43 that lead to abnormally regulated cell-cell communication are associated with a number of diseases. One of them is oculodentodigital dysplasia (ODDD) and characterized by facial appearance include a pointed nose, undeveloped teeth and digital malformation or webbing between fourth and fifth fingers $[5,6]$.

Beyond the skeleton, Impaired Cx43 expression or loss of function has been implicated in several types of cancers. Cx43 mutations are also involved in sudden infant death syndrome (SIDS) in one year old or smaller babies, although the mechanism is still unexplained [7].

Our lab is interested in the role of $\mathrm{Cx} 43$ in cells of the musculoskeletal system, including bone and cartilage. Recently, we investigated how cAMP second messenger communicated by bone cells via $\mathrm{C} \times 43$ where it can impact osteoblast function. We showed that overexpression of Cx43 in bone cells enhanced the activity of cAMP-response element driven transcriptional luciferase reporter (CRE-luc) and increased phospho-CREB and phospho-ERK1/2 expression by immunoblotting following treatment with prostaglandin E2 (PGE2) and forskolin. The Cx43-dependent potentiation of signalling following PGE2 treated cells was not accompanied by further increase in CAMP levels, suggesting that the CAMP was shared between the cells rather than $\mathrm{Cx} 43$ enhancing CAMP production. In support of this point, using a novel coculture assay in which one set of cells express a constitutively active Gs-alpha (donor cells) and a second set of cells express a cAMP-response element driven transcriptional reporter (acceptor cells), we showed that when both the Gs-alpha expressing donor cell and CRE-luc expressing acceptor cell express $\mathrm{Cx} 43$, then we could detect robust activation of the CRE-luc reporter the acceptor cell, indicating communication of the CAMP-dependent signal. This stimulation was not seen when the donor and acceptor cells were co-cultured in a transwell chamber where cell-to-cell contacts were not formed between the donor and acceptor cell populations. Finally, we showed that $\mathrm{Cx} 43$ increased the cAMP-dependent expression of RANKL in osteoblastic cells in culture, and enhanced the repression of Sost, implying a potential mechanism for the modulation of tissue remodelling. In total, these data demonstrate that $\mathrm{C} \times 43$ can communicate cAMP to impact signal transduction cascades and the expression of key bone effector molecules [8].

In addition, our laboratory is interested in examining the role of gap junction protein $\mathrm{C} \times 43$ and its upregulation in cells of the joint during osteoarthritis (OA). We showed that increasing Cx43 levels in synovial cells is sufficient to enhance the expression of OA-associated catabolic and inflammatory genes. Our results and data of other lab suggested that $\mathrm{C} \times 43$ could influence the expression of genes associated with OA. Interestingly, this is the first study to show that $\mathrm{Cx} 43$ abundance can impact the expression PTGS2, MMP1, MMP13, ADAMTS4, ADAMTS5, IL1 and IL6 while knockdown of Cx43 could decrease the expression of these genes by quantitative RT-PCR methods. Thus, targeting $\mathrm{Cx} 43$ may be therapeutic strategy for OA patients [9].

Overall, these studies will provide insight on mechanistic information on how cell-to-cell communication can influence 
cell function and cause disease. Our aim is to develop a strategy to compensate for these diseases caused by aberrant expression or mutations of $\mathrm{Cx} 43$.

\section{References:}

1. Koval M, Geist ST, Westphale EM, Kemendy AE, Civitelli R, et al. Transfected connexin45 alters gap junction permeability in cells expressing endogenous connexin43, J.Cell Biol 130,1995, 987-995.

2. Goldberg GS, Valiunas V, Brink PR (2004) Selective permeability of gap junction channels, Biochim.Biophys. Acta 1662: 96-10.

3. Stains JP, Civitelli R (2016) Connexins in the skeleton, seminars in cell \& Developmental Biology 50: 31-39.

4. Stains JP, Watkins MP, Grimston SK, Hebert C, Civitelli R (2014) Molecular mechanisms of osteoblast/osteocyte regulation by connexin43, calcif. Tissue Int 94: 55-67.
5. Laird DW Syndromic and non-syndromic disease-linked Cx43 mutations, FEBS letter 588, 2014, 1339-1348.

6. Flenniken AM, Osborne LR, Anderson N, Ciliberti N, Fleming C, et al. (2005) A Gja1 missense mutation in a mouse model of oculodentodigital dysplasia, Development 132: 4375-4386.

7. Van Norstrand DW, Asimaki A, Rubinos C, Dolmatova E, Srinivas M, Tester DJ, Saffitz JE, Duffy HS, Ackerman MJ, Connexin43 mutation causes heterogeneous gap junction loss and sudden infant death, Circulation, 125,2012, 474-81.

8. Gupta A, Anderson H, Ren M, Stains JP (2015) Communication of cyclic AMP by connexin43 gap junctions influences osteoblast signaling and gene expression, J. Bone Miner. Res., 30: e041.

9. Gupta A, Niger C, Buo AM, Eideiman ER, Chen RJ, et al. (2014) Connexin43 enhances the expression of osteoarthritisassociated genes in synovial fibroblasts in culture, BMC Musculoskeletal Disorders 15: 425. 